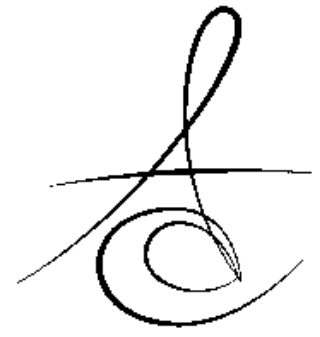

\title{
MAKSİLLOFASİYAL FRAKTÜRLERİN KONİK IŞINLI BİLGİSAYARLI TOMOGRAFİ İLE RETROSPEKTİF OLARAK DEĞERLENDİRİLMESİ
}

\author{
RETROSPECTIVE ASSESSMENT OF MAXILLOFACIAL FRACTURES WITH \\ CONE-BEAM COMPUTED TOMOGRAPHY
}

\author{
Arş. Gör. Uzm. Dt. Melih ÖZDEDE* \\ Doç. Dr. Zühre AKARSLAN*
}

\author{
Arş. Gör. Uzm. Dt. Çiğdem SARIKIR* \\ Doç. Dr. İlkay PEKER*
}

Makale Kodu/Article code: 2527

Makale Gönderilme tarihi: 23.12.2015

Kabul Tarihi: 16.02 .2016

\section{ÖZET}

Amaç: Maksillofasiyal bölgede meydana gelen travmalarda klinik muayenenin yanı sıra radyolojik değerlendirme yapmak gerekmektedir. Üç boyutlu görüntüleme yöntemleri ile fraktür hatlarının ve fragmanların varlığı, yeri ve oryantasyonu süperpozisyon olmadan değerlendirilebilmektedir. Konik ışınlı bilgisayarlı tomografi, dental ve maksillofasiyal bölgenin üç boyutlu görüntülemesini sağlayan bir tekniktir. Bu çalışmanın amacı, maksillofasiyal fraktürlerin karakteristiklerinin konik ışınlı bilgisayarlı tomografi ile incelenmesidir.

Gereç ve Yöntem: Bu çalışmada, Ağız, Diş ve Çene Radyolojisi Anabilim Dalı Radyoloji Arşivi'nde maksillofasiyal fraktür şüphesiyle konik ışınlı bilgisayarlı tomografi görüntüleri elde edilmiş olan 71 hastanın görüntüsü incelendi. Hastaların demografik bilgileri ve fraktür varlığı kaydedildi. Fraktür teşhis edilen hastalarda, fraktürün yeri, simetrisi ve anatomik yapılardaki deplasmanları değerlendirildi.

Bulgular: İncelenen hastaların \%83.1'inde $(n=59)$ toplam 125 fraktür hattı belirlendi. Yaşları 4 ile 76 (ortalama: 30) arasında değişen hastaların \%32.2'si $(n=19)$ kadın, \%67.8'i $(n=40)$ erkekti. Fraktürlerin en sık görüldüğü yerler sırasıyla; kondil başı-kondil boynu (\%20.0; $n=25)$, subkondiler bölge $(\% 12.8 ; n=16)$ ve pterigoid prosesler $(\% 9.6, \mathrm{n}=12)$ idi. Fraktürlerin $\% 48.8^{\prime}$ inde $(n=61)$ anatomik yapılarda deplasman mevcuttu.

Sonuç: $\mathrm{Bu}$ çalışmada değerlendirilen fraktür vakalarının çoğunluğunun orta yaş erkeklerde ve mandibulada lokalize olduğu belirlendi. Diş hekimleri ve tıp hekimlerinin konik ışınlı bilgisayarlı tomografinin maksillofasiyal fraktürlerdeki kullanımı hakkında bilgi sahibi olması diagnostik açıdan yararlı olacaktır.

Anahtar kelimeler: Konik Işınlı Bilgisayarlı Tomografi; Fraktürler; Maksillofasiyal Yaralanmalar

\section{ABSTRACT}

Aim: Radiographic examination is essential for evaluating trauma of the maxillofacial region in addition to clinical examination. The presence, location and orientation of fracture planes and fragments can be assessed with three dimensional imaging modalities without superposition. Cone-beam computed tomography is a technique that provides three-dimensional imaging of the dental and maxillofacial region. The aim of this study was to evaluate the characteristics of maxillofacial fractures with the aid of cone beam computed tomography images.

Material and Methods: Cone-beam computed tomographic images present in the archive of the Dentomaxillofacial Radiology department belonging to 71 patients with suspected maxillofacial fractures were evaluated in this study. Demographic characteristics of the patients and presence of any fracture was recorded. Cases in which fracture was diagnosed, the location and symmetry of the fracture and any displacement of the anatomic structures were recorded also.

Results: Fractures were determined in 59 (83.1\%) patients, totally 125 fractures. These patients consisted of 19 (32.2\%) females and 40 (67.8\%) males with and age range of 4-76 (mean: 30). The most common locations of the fractures were found to be the condyle head-condyle neck $(20.0 \%, n=25)$, subcondylar region $(12.8 \%, \mathrm{n}=16)$ and the pterygoid processes $(9.6 \%, n=12)$ regions. Sixty-one $(48.8 \%)$ of the fractures showed displacement of the structures.

Conclusion: This study evaluated the fracture cases were identified where the majority of middle-aged men and mandible localized. Knowledge of dentists and medical doctors about the use of the cone-beam computed tomography of maxillofacial fractures, would be useful for diagnosis.

Keywords: Cone-Beam Computed Tomography; Fractures; Maxillofacial Injuries

\footnotetext{
* Gazi Üniversitesi Diş Hekimliği Fakültesi, Ağız, Diş ve Çene Radyolojisi AD
} 


\section{GİRIŞ}

Travma ya da bir patoloji nedeniyle kemik bütünlüğünün bozulmasına "kırık" veya "fraktür" denir ${ }^{1}$. Maksillofasiyal bölge insanlarda en çok travmaya maruz kalan bölgelerden birisidir². Maksillofasiyal bölgede meydana gelen travmalarda ayrıntılı radyolojik inceleme yapmak gerekmektedir ${ }^{3}$.

Travma vakalarında radyolojik incelemede fraktürün varlığı, lokalizasyonu, tipi, yumuşak dokulara saplanan yabancı cisimler, fragmanların yer değiştirmesi ve vital anatomik yapılarla olan ilişkisi belirlenebilir. Aynı zamanda, travma sonrası iyileşme ve uzun dönem takip yapılabilir ${ }^{1,3}$.

Maksillofasiyal fraktürlerin teşhisinde periapikal, oklüzal, postero-anteriyor, lateral kafa grafisi ve panoramik radyografi gibi konvansiyonel radyografik yöntemlerin yanı sıra, ileri görüntüleme yöntemlerinden bilgisayarlı tomografi (BT) kullanılabilir ${ }^{1}$. Konvansiyonel radyografik yöntemler kullanılacaksa birbirine dik açılı en az iki görüntü elde edilmelidir. Panoramik radyografi, ilk aşamada fraktürün yerinin tespitinde kullanışlı olmakla birlikte, özellikle çenelerin anterior bölgesindeki düşük rezolüsyonu, diagnostik değerini sınırlamaktadır. Çenelerde birden fazla olan veya kompleks fraktürlerde BT gibi üç boyutlu görüntüleme yöntemleri tercih edilmelidir. Son yıllarda, radyasyon dozu, görüntü kalitesi ve hasta rahatlığı açısından BT'ye göre daha avantajlı olan konik ışınlı bilgisayarlı tomografi (KIBT) tekniği öne çıkmıştır ${ }^{3}$.

Bilgimiz dâhilinde, literatürde maksillofasiyal fraktürlerin KIBT ile değerlendirildiği az sayıda araştırma bulunmaktadır ve bu çalışmalarda genellikle dental fraktürler incelenmiştir ${ }^{4,5}$. Bu çalışmanın amacı, maksillofasiyal bölgedeki fraktürlerin radyografik özelliklerini KIBT ile retrospektif olarak değerlendirmektir.

\section{GEREÇ VE YÖNTEM}

Bu çalışmada Gazi Üniversitesi Diş Hekimliği Fakültesi Ağız, Diş ve Çene Radyolojisi Anabilim Dalı Radyoloji Arşivi'nde 2012-2015 yılları arasında elde edilmiş 4099 KIBT görüntüsü arasından, fraktür şüphesi nedeniyle KIBT görüntüsü istenen 71 hastaya ait görüntü retrospektif olarak incelendi. KIBT görüntüleri, Planmeca ProMax 3D Mid (Planmeca Oy, Helsinki, Finlandiya) cihazı ile 20x17 cm'lik görüntüleme alanına sahip, $90 \mathrm{kVp}, 12 \mathrm{~mA}, 27.6$ sn'lik ışınlama süresi ve
$0.4 \times 0.4 \times 0.4 \mathrm{~mm}$ voksel boyutunda elde edilmiş görüntülerdi.

Çalışmadaki tüm radyografik değerlendirmeler, KIBT görüntüleri konusunda üç yıl deneyimli olan Ağız, Diş ve Çene Radyolojisi Uzmanı iki diş hekiminin (MÖ ve ÇS) fikir birliği ile ışığı azaltılmış sakin bir ortamda, Philips model, NVIDIA Quadro FX 380 ekran kartına sahip 24 inç büyüklüğündeki medikal monitör kulanılarak, ekrana $50 \mathrm{~cm}$ uzaklıktan yapıldı. Araştırmacılar arasında fikir birliği sağlanamayan durumlarda en az 15 yıl deneyimli iki Ağız, Diş ve Çene Radyolojisi Uzmanı'na (İP ve ZA) başvuruldu. Tüm görüntüler bu şartlarda aksiyal, koronal ve sagital kesitlerde incelendi.

Çalışmada teşhis edilen fraktürler, Harorlı ve arkadaşlarının $^{1}$ fraktür sınıflaması modifiye edilerek sınıflandırıldı:

1- Mandibula fraktürleri: Angulus mandibula, kanin bölgesi, alveolar proses, koronoid proses, korpus mandibula, simfiz mandibula ve ramus mandibula bölgesindeki fraktürler.

2- Kondil fraktürleri: Kondil başı-kondil boynu ve subkondiler bölgede görülen fraktürler.

3- Maksillofasiyal fraktürler: Alveolar proses, pterigoid proses, maksiller sinüs duvarı, izole damak kubbesi, nazal kavite, zigoma ve orbita bölgesinde görülen fraktürler.

Resim 1, 2, 3, 4 ve 5'te çalışmada belirlenen fraktürlere örnekler verilmiştir.

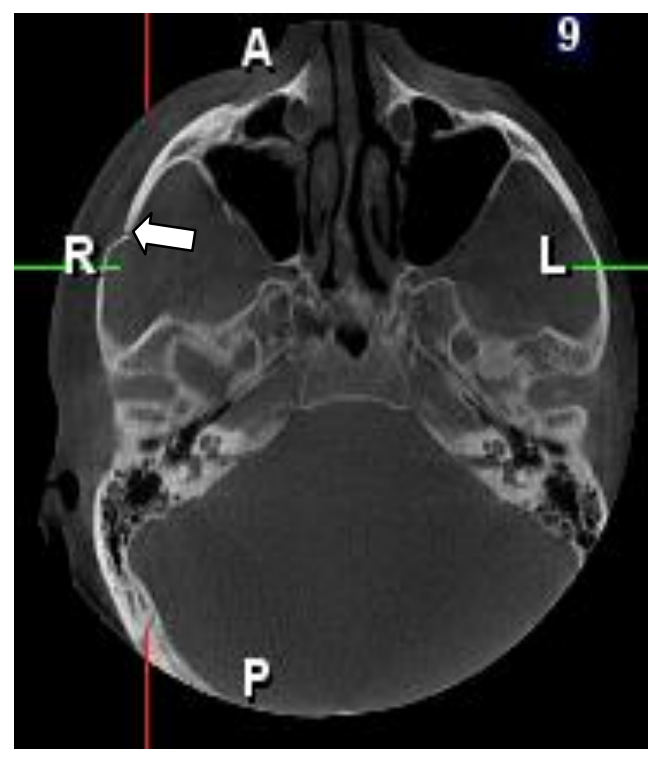

Resim 1. Zigomada izlenen fraktürün aksiyal kesitteki KIBT görüntüsü (ok) 

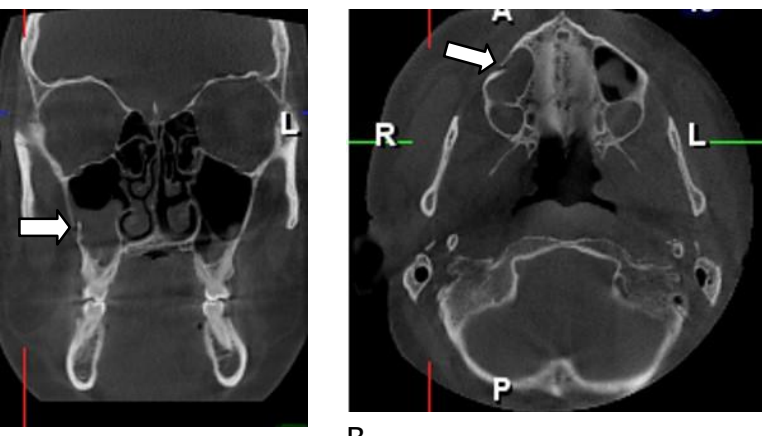

A

B

Resim 2. Sağ maksiller sinüs duvarında izlenen fraktürün (A) koronal ve (B) aksiyel kesitteki KIBT görüntüsü (ok)

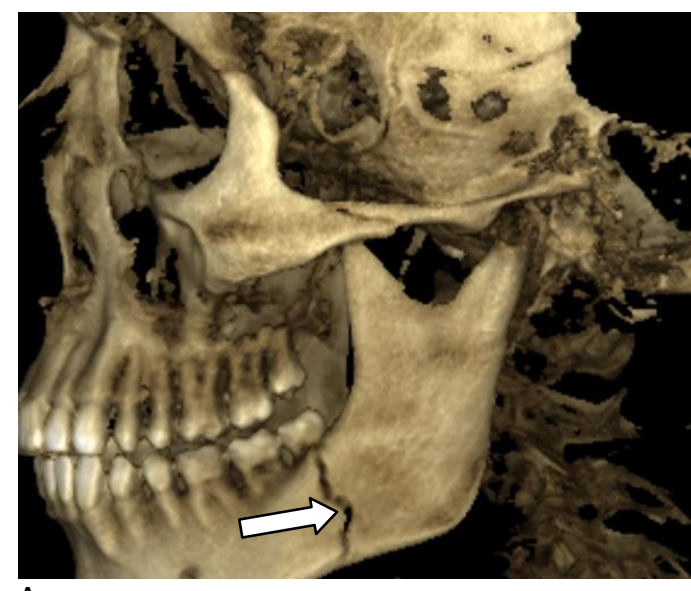

A

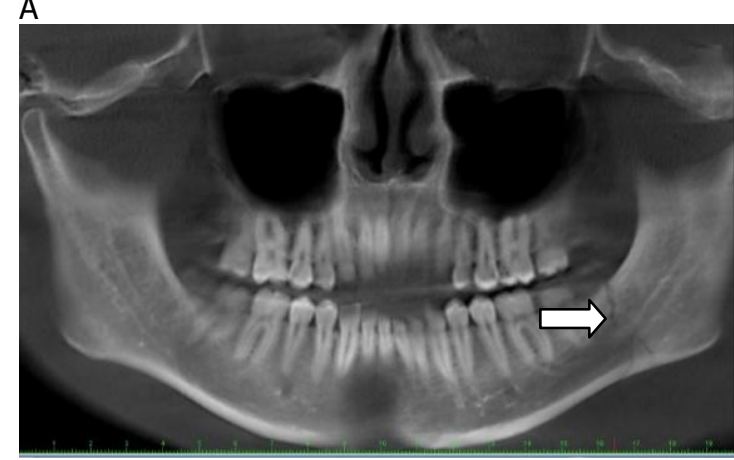

B

Resim 3. Sol mandibulada izlenen fraktürün (A) üç boyutlu sagital ve (B) panoramik kesitteki KIBT görüntüsü (ok)

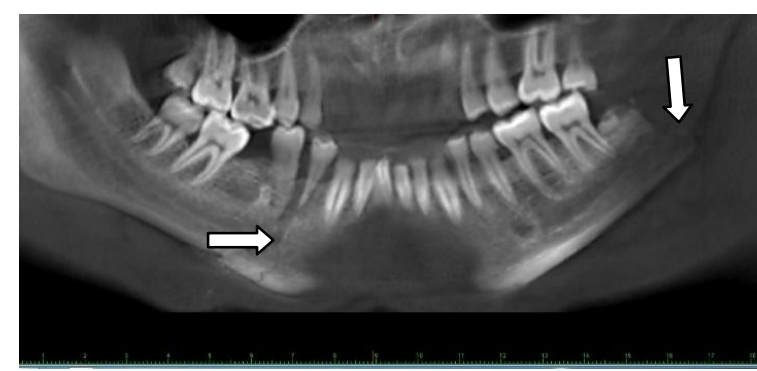

A

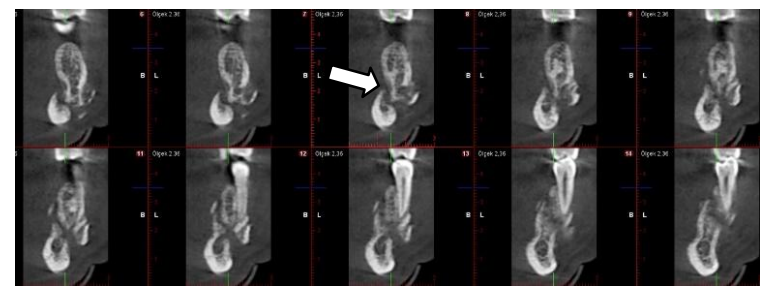

B

Resim 4. Sağ ve sol mandibulada izlenen fraktürün (A) panoramik ve (B) sağ mandibulanın krosseksiyonel kesitteki KIBT görüntüsü (ok)

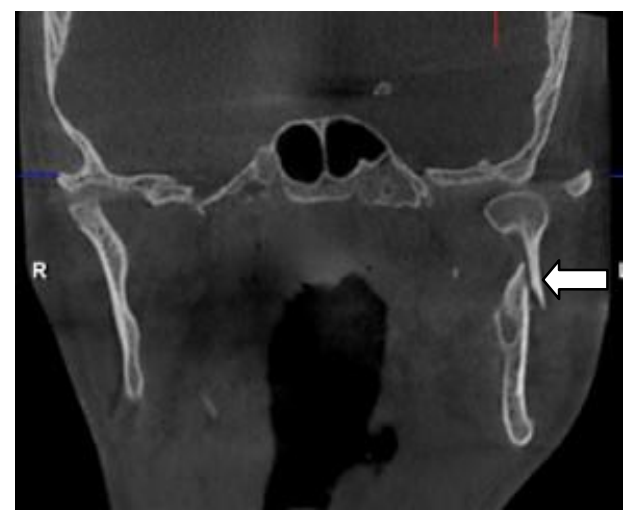

Resim 5. Sol mandibuler kondil boynunda izlenen fraktürün koronal kesitteki KIBT görüntüsü (ok)

Tespit edilen fraktürler, simetrisine (unilateral veya bilateral) ve deplasman varlığına göre kaydedildi. Aynı zamanda, fraktürlerin yaşa ve cinsiyete göre dağıIımı incelendi. Fraktür tespit edilen hastalar yaşlarına göre 4-18, 19-35 ve 35-76 yaş arası olmak üzere üç gruba ayrıldı. Elde edilen veriler deskriptif analiz ile değerlendirildi.

\section{BULGULAR}

Fraktür şüphesi nedeniyle KIBT görüntüsü elde edilmiş 71 hastanın \%83'ünde $(n=59)$ maksillofasiyal bölgede en az bir fraktür olmak üzere, toplamda 125 fraktür hattı tespit edildi. Yaş ortalaması 30 olan, 4 ile 76 yaşları arasındaki hastaların \% 32.2'si $(n=19)$ kadın, \%67.8'i $(n=40)$ erkekti. Tüm fraktürler 19-35 yaş arası bireylerde ve erkeklerde daha fazla izlendi (Tablo 1). Fraktürlerin \%66.4'ü $(n=83)$ unilateral iken, \%33.6'sı ( $n=21)$ bilateraldi; \%48.8'inde $(n=61)$ deplasman görüldü. (Tablo 2).

Hastaların \%55.9'unda ( $n=33$ ) tek, \%44.1'inde $(n=26)$ ise birden fazla fraktür hattı görüldü. İncelenen fraktürlerin \%60.8'i ( $n=76$ ) mandibulada lokalize idi. Mandibuladaki fraktürler en fazla kondil başı-kondil

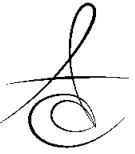


boynunda (\%20.0, n=25) görülürken; bunu subkondiler bölge (\%12.8, $\mathrm{n}=16)$, angulus mandibula (\%8.0, $\mathrm{n}=10$ ) ve korpus mandibula (\%8.0, $\mathrm{n}=10$ ) izlemekteydi. Mandibula dışında en sık fraktür tespit edilen yerler; pterigoid proses (\%9.6, $\mathrm{n}=12$ ), ve zigoma (\%8.0, $\mathrm{n}=10)$ idi. En az fraktür görülen bölgeler ise, birer tane fraktür görülen $(\% 0.8, \mathrm{n}=1)$ mandibular ramus, mandibular alveolar proses ve damak kubbesi olarak belirlendi. Fraktür lokalizasyonunun yaş ve cinsiyete göre dağıımının detayları tabloda gösterilmiştir (Tablo 3).

Tablo 1. Fraktür bölgelerinin yaş ve cinsiyete göre dağılımı

\begin{tabular}{|c|c|c|c|c|c|}
\hline \multirow{2}{*}{\multicolumn{2}{|c|}{$\begin{array}{l}\text { Yaş ve } \\
\text { Cinsiyet }\end{array}$}} & \multicolumn{4}{|c|}{$\begin{array}{l}\text { Fraktür Bölgesi } \\
\text { N (\%)* }\end{array}$} \\
\hline & & \multirow{2}{*}{$\begin{array}{c}\text { Mandibula } \\
12 \\
(\% 9.6)\end{array}$} & \multirow{2}{*}{$\begin{array}{c}\text { Kondil } \\
6 \\
(\% 4.8)\end{array}$} & \multirow{2}{*}{$\begin{array}{c}\begin{array}{c}\text { Maksillo- } \\
\text { fasiyal }\end{array} \\
1 \\
(\% 0.8)\end{array}$} & \multirow{2}{*}{$\begin{array}{c}\text { Toplam } \\
19 \\
(\% 15.2)\end{array}$} \\
\hline \multirow{3}{*}{$\begin{array}{c}\text { Yaş } \\
\text { Grupları }\end{array}$} & 4-18 & & & & \\
\hline & $19-35$ & $\begin{array}{c}24 \\
(\% 19.2) \\
\end{array}$ & $\begin{array}{c}9 \\
(\% 7.2)\end{array}$ & $\begin{array}{c}27 \\
(\% 21.6) \\
\end{array}$ & $\begin{array}{c}60 \\
(\% 48.0)\end{array}$ \\
\hline & $35-76$ & $\begin{array}{c}15 \\
\% 12.0) \\
\end{array}$ & $\begin{array}{c}10 \\
(\% 8.0)\end{array}$ & $\begin{array}{c}21 \\
(\% 16.8)\end{array}$ & $\begin{array}{c}46 \\
(\% 36.8)\end{array}$ \\
\hline \multirow{3}{*}{ Cinsiyet } & Kadın & $\begin{array}{c}12 \\
(\% 9.6) \\
\end{array}$ & $\begin{array}{c}9 \\
(\% 7.2) \\
\end{array}$ & $\begin{array}{c}2 \\
(\% 1.6) \\
\end{array}$ & $\begin{array}{c}23 \\
(\% 18.4)\end{array}$ \\
\hline & Erkek & $\begin{array}{c}39 \\
(\% 31.2) \\
\end{array}$ & $\begin{array}{c}16 \\
(\% 12.8) \\
\end{array}$ & $\begin{array}{c}47 \\
(\% 37.6)\end{array}$ & $\begin{array}{c}102 \\
(\% 81.6)\end{array}$ \\
\hline & Toplam & $\begin{array}{c}51 \\
(\% 40.8)\end{array}$ & $\begin{array}{c}25 \\
(\% 20.0)\end{array}$ & $\begin{array}{c}49 \\
(\% 39.2)\end{array}$ & $\begin{array}{c}125 \\
(\% 100.0)\end{array}$ \\
\hline
\end{tabular}

*Yüzdeler, ondalık dilimlere göre verilmiştir.
Tablo 2. Fraktürlerin simetrisinin ve deplasman varlığının, yaş ve cinsiyete göre dağııımı

\begin{tabular}{|c|c|c|c|c|c|}
\hline \multirow{2}{*}{\multicolumn{2}{|c|}{$\begin{array}{l}\text { Yaş ve } \\
\text { Cinsiyet }\end{array}$}} & \multicolumn{2}{|c|}{$\begin{array}{l}\text { Fraktürün Simetrisi } \\
\text { N (\%)* }\end{array}$} & \multicolumn{2}{|c|}{$\begin{array}{c}\text { Fragmanlarda } \\
\text { Deplasman Varlığı } \\
\text { N }(\%)^{*}\end{array}$} \\
\hline & & Unilateral & Bilateral & $\begin{array}{c}\text { Deplasman } \\
\text { var }\end{array}$ & $\begin{array}{c}\text { Deplasman } \\
\text { yok }\end{array}$ \\
\hline \multirow{3}{*}{$\begin{array}{c}\text { Yaş } \\
\text { Grupları }\end{array}$} & 4-18 & $\begin{array}{c}13 \\
(\% 10.4)\end{array}$ & $\begin{array}{c}3 \\
(\% 4.8) \\
\end{array}$ & $\begin{array}{c}12 \\
(\% 9.6)\end{array}$ & $\begin{array}{c}7 \\
(\% 5.6) \\
\end{array}$ \\
\hline & $19-35$ & $\begin{array}{c}40 \\
(\% 32.0)\end{array}$ & $\begin{array}{c}10 \\
(\% 16.0)\end{array}$ & $\begin{array}{c}27 \\
(\% 21.6)\end{array}$ & $\begin{array}{c}33 \\
(\% 26.4)\end{array}$ \\
\hline & $35-76$ & $\begin{array}{c}30 \\
(\% 24.0)\end{array}$ & $\begin{array}{c}8 \\
(\% 12.8)\end{array}$ & $\begin{array}{c}22 \\
(\% 17.6)\end{array}$ & $\begin{array}{c}24 \\
(\% 19.2)\end{array}$ \\
\hline \multirow{3}{*}{ Cinsiyet } & Kadın & $\begin{array}{c}21 \\
(\% 16.8)\end{array}$ & $\begin{array}{c}2 \\
(\% 3.2)\end{array}$ & $\begin{array}{c}17 \\
(\% 13.6)\end{array}$ & $\begin{array}{c}8 \\
(\% 6.4) \\
\end{array}$ \\
\hline & Erkek & $\begin{array}{c}62 \\
(\% 49.6)\end{array}$ & $\begin{array}{c}19 \\
(\% 30.4)\end{array}$ & $\begin{array}{c}44 \\
(\% 35.2)\end{array}$ & $\begin{array}{c}56 \\
(\% 44.8) \\
\end{array}$ \\
\hline & Toplam & $\begin{array}{c}83 \\
(\% 66.4)\end{array}$ & $\begin{array}{c}21 \\
(\% 33.6)\end{array}$ & $\begin{array}{c}61 \\
(\% 48.8)\end{array}$ & $\begin{array}{c}64 \\
(\% 51.2)\end{array}$ \\
\hline
\end{tabular}

*Yüzdeler, ondalık dilimlere göre verilmiştir.

Not: Bazı hastalarda bilateral ya da birden fazla fraktür aynı anda bulunduğu için tabloda verilen değerlerin sayı ve yüzdelerin toplamı 100'ün üzerindedir.

Tablo 3. Fraktür lokalizasyonunun yaş ve cinsiyete göre dağııııı

\begin{tabular}{|c|c|c|c|c|c|c|c|c|c|c|c|c|c|c|c|c|c|c|}
\hline \multirow{2}{*}{\multicolumn{2}{|c|}{\begin{tabular}{|c} 
Yaş ve \\
Cinsiyet
\end{tabular}}} & \multicolumn{17}{|c|}{$\begin{array}{c}\text { Fraktür Lokalizasyonu } \\
\text { N }(\%)^{*}\end{array}$} \\
\hline & & 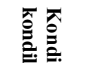 & $\frac{\mathscr{E}}{E}$ & $\Xi \bar{s}$ & $\pi$ & 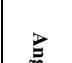 & $\pi$ & $g \frac{2}{4}$ & 종 & $\varrho$ & $\bar{E}=$ & $\Xi \underset{5}{\square}$ & & $=3$ & 资: & $\underline{N}$ & & 3 \\
\hline \multirow{3}{*}{ 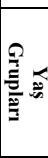 } & $4-18$ & $\begin{array}{c}6 \\
(\% 4.8) \\
\end{array}$ & $\begin{array}{c}3 \\
(\% 2.4) \\
\end{array}$ & - & - & $\begin{array}{c}2 \\
(\% 1.6) \\
\end{array}$ & $\begin{array}{c}4 \\
(\% 3.2) \\
\end{array}$ & - & - & $\begin{array}{c}3 \\
(\% 2.4) \\
\end{array}$ & - & - & - & - & - & $\begin{array}{c}1 \\
(\% 0.8) \\
\end{array}$ & - & $\begin{array}{c}19 \\
(\% 15.2) \\
\end{array}$ \\
\hline & $19-35$ & $\begin{array}{c}9 \\
(\% 7.2) \\
\end{array}$ & $\begin{array}{c}6 \\
(\% 4.8) \\
\end{array}$ & $\begin{array}{c}1 \\
(\% 0.8) \\
\end{array}$ & $\begin{array}{c}1 \\
(\% 0.8)\end{array}$ & $\begin{array}{c}5 \\
(\% 4.0)\end{array}$ & $\begin{array}{c}5 \\
(\% 4.0)\end{array}$ & - & $\begin{array}{c}6 \\
(\% 4.8) \\
\end{array}$ & $(102.4)$ & - & $\begin{array}{c}12 \\
(\% 9.6)\end{array}$ & $\begin{array}{c}3 \\
(\% 2.4)\end{array}$ & $\begin{array}{c}1 \\
(\% 0.8)\end{array}$ & $\begin{array}{c}6 \\
(\% 4.8)\end{array}$ & $\begin{array}{c}4 \\
(\% 3.2)\end{array}$ & $\begin{array}{c}5 \\
(\% 4.0)\end{array}$ & $\begin{array}{c}64 \\
(\% 51.2)\end{array}$ \\
\hline & $35-76$ & $\begin{array}{c}10 \\
(\% 8.0)\end{array}$ & $\begin{array}{c}7 \\
(\% 5.6)\end{array}$ & $\begin{array}{c}1 \\
(\% 0.8)\end{array}$ & - & $\begin{array}{c}3 \\
(\% 2.4)\end{array}$ & $\begin{array}{c}1 \\
(\% 0.8) \\
\end{array}$ & $\begin{array}{c}1 \\
(\% 0.8)\end{array}$ & $\begin{array}{c}1 \\
(\% 0.8) \\
\end{array}$ & $\begin{array}{c}1 \\
(\% 0.8)\end{array}$ & $\begin{array}{c}1 \\
(\% 0.8)\end{array}$ & - & $\begin{array}{c}3 \\
(\% 2.4) \\
\end{array}$ & $\begin{array}{c}4 \\
(\% 3.2)\end{array}$ & $\begin{array}{c}2 \\
(\% 1.6)\end{array}$ & $\begin{array}{c}5 \\
(\% 4.0) \\
\end{array}$ & $\begin{array}{c}2 \\
(\% 1.6)\end{array}$ & $\begin{array}{c}42 \\
(\% 33.6)\end{array}$ \\
\hline \multirow{3}{*}{ 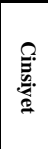 } & Kadın & $\begin{array}{c}11 \\
(\% 8.8)\end{array}$ & $\begin{array}{c}4 \\
(\% 3.2)\end{array}$ & $\begin{array}{c}1 \\
(\% 0.8)\end{array}$ & $\begin{array}{c}1 \\
(\% 0.8)\end{array}$ & $\begin{array}{c}2 \\
(\% 1.6)\end{array}$ & $\begin{array}{c}1 \\
(\% 0.8)\end{array}$ & - & $\begin{array}{c}1 \\
(\% 0.8)\end{array}$ & $\begin{array}{c}2 \\
(\% 1.6)\end{array}$ & - & - & - & $\begin{array}{c}1 \\
(\% 0.8)\end{array}$ & $\begin{array}{c}1 \\
(\% 0.8)\end{array}$ & - & - & $\begin{array}{c}25 \\
(\% 20.0)\end{array}$ \\
\hline & Erkek & $\begin{array}{c}14 \\
(\% 11.2)\end{array}$ & $\begin{array}{c}12 \\
(\% 9.6)\end{array}$ & $\begin{array}{c}1 \\
(\% 0.8)\end{array}$ & - & $\begin{array}{c}8 \\
(\% 6.4)\end{array}$ & $\begin{array}{c}9 \\
(\% 7.2)\end{array}$ & $\begin{array}{c}1 \\
(\% 0.8)\end{array}$ & $\begin{array}{c}6 \\
(\% 4.8)\end{array}$ & $\begin{array}{c}2 \\
(\% 1.6)\end{array}$ & $\begin{array}{c}1 \\
(\% 0.8)\end{array}$ & $\begin{array}{c}12 \\
(\% 9.6)\end{array}$ & $\begin{array}{c}6 \\
(\% 4.8)\end{array}$ & $\begin{array}{c}4 \\
(\% 3.2)\end{array}$ & $\begin{array}{c}7 \\
(\% 5.6)\end{array}$ & $\begin{array}{c}10 \\
(\% 8.0)\end{array}$ & $\begin{array}{c}7 \\
(\% 5.6)\end{array}$ & \begin{tabular}{|c|c}
100 \\
$(\% 80.0)$
\end{tabular} \\
\hline & Toplam & $\begin{array}{c}25 \\
(\% 20.0)\end{array}$ & $\begin{array}{c}16 \\
(\% 12.8)\end{array}$ & $\begin{array}{c}2 \\
(\% 1.6)\end{array}$ & $\begin{array}{c}1 \\
(\% 0.8)\end{array}$ & $\begin{array}{c}10 \\
(\% 8.0)\end{array}$ & $\begin{array}{c}10 \\
(\% 8.0)\end{array}$ & $\begin{array}{c}1 \\
(\% 0.8)\end{array}$ & $\begin{array}{c}7 \\
(\% 6.0) \\
\end{array}$ & $\begin{array}{c}4 \\
(\% 3.2)\end{array}$ & $\begin{array}{c}1 \\
(\% 0.8)\end{array}$ & $\begin{array}{c}12 \\
(\% 9.6)\end{array}$ & $\begin{array}{c}6 \\
(\% 4.8) \\
\end{array}$ & $\begin{array}{c}5 \\
(\% 4.0)\end{array}$ & $\begin{array}{c}8 \\
(\% 6.4)\end{array}$ & $\begin{array}{c}10 \\
(\% 8.0) \\
\end{array}$ & $\begin{array}{c}7 \\
(\% 5.6 \\
\end{array}$ & $\begin{array}{c}125 \\
(\% 100.0)\end{array}$ \\
\hline
\end{tabular}

*Yüzdeler, ondalık dilimlere göre verilmiştir. 


\section{TARTIŞMA}

Literatürde maksillofasiyal fraktürlerin radyolojik olarak değerlendirildiği çalışmalarda çoğunlukla BT yöntemi kullanılmıştır. Maksillofasiyal fraktürlerin KIBT ile değerlendirildiği çalışmalarda araştırmacılar genellikle dental fraktürlere odaklanmışlardır ${ }^{4-6}$. Bu konuda genellikle olgu sunumları, derlemeler, panoramik radyografi, BT ve KIBT'nin etkinliğinin karşılaştırıldığı çaIışmalar yapılmıştır ${ }^{7-10}$. Bu çalışmada ise maksillofasiyal fraktürler KIBT görüntülerinde retrospektif olarak incelendi.

$\mathrm{Bu}$ çalışmada fraktür teşhis edilen hastaların \%67.8'i erkek, \%32.2'si kadın hasta idi. Hastaların yaş ortalaması 30 olarak bulundu. Erol ve arkadaşlarının ${ }^{11}$ yaptıkları araştırmada da fraktür görülen hastaların çoğunluğunun (\%79.0) erkek olduğunu bildirilmiştir. Iida ve arkadaşlarının ${ }^{12}$ çalışmasında erkek/kadın oranı 2.8/1, Olasoji ve arkadaşlarında ${ }^{13}$ bu oran $2.19 / 1$, Demir ve arkadaşlarında ${ }^{14}$ ise $2.78 / 1$ olarak belirtilmiştir. Bu çalışmadaki sonuçlar diğer çalışmalarla uyumluluk göstermektedir.

Maksillofasiyal fraktürlerin incelendiği çalışmalarda farklı araştırmacılar tarafından farklı yöntemler ve farklı sınıflamalar kullanılmıştır. Bu çalışmada, Harorlı ve arkadaşlarının ${ }^{1}$ fraktür sınıflaması modifiye edilerek kullanıldı. Bu sınıflamaya göre, KIBT görüntülerinde izlenen fraktürlerin \%60.8'i mandibulayı etkilemişti. Mandibuladaki fraktürler de en fazla kondil başı-kondil boynunda görülürken, bunu subkondiler bölge, angulus mandibula ve korpus mandibula izlemekteydi. Mandibula dışında en sık fraktür tespit edilen yerler ise pterigoid proses ve zigoma idi.

Yaman ve arkadaşlarının², Ağız, Diş ve Çene Hastalıkları ve Cerrahisi kliniğinde, maksillofasiyal fraktürü olan 577 hastanın klinik muayene ve panoramik radyografi bulgularını değerlendirdikleri çalışmalarında, hastaların \%27.2'sinin kadın, \%72.8'inin erkek olduğu, \%78.0'inde mandibulada, \%25.0'inde ise mandibular kondilde fraktür tespit edildiği bildirilmiştir. Demir ve arkadaşlarının ${ }^{14}$, Plastik Cerrahi kliniğinde yaptıkları çalışmada maksillofasiyal fraktürü bulunan, 4 ile 82 yaşları arasındaki (yaş ortalaması 30.5 olan) 89'u (\%74.0) erkek ve 32'si (\%26.0) kadın olan 121 hastayı inceledikleri araştırmada, fraktürlerin \%42.9'unun mandibulada, \%30.5'inin zigomada ve \%26.4'ünün maksillada olduğu bildirilmiştir. Aynı çalışmada, mandibuladaki fraktürlerin \%32.0'si parasimfiz, \%16.0'sı angulus, \%16.0'sı korpus, \%14.0'ü kondil ve $\% 12.0$ 'si ramus bölgesinde saptanmıştır. Zigoma fraktürlerinin \%38.0'i mandibular rim, \%33.0'ü zigomatik ark ve \%21.0'i orbita tabanında tespit edilmiştir. Maksiller fraktürlerin ise \%43.0'ünün Le Fort 1 ve \%28.0'inin Le Fort 2 fraktürü olduğu gözlenmiştir. Li ve arkadaşlarının ${ }^{15}$, maksillofasiyal travma geçirmiş 3958 vakayı değerlendirdikleri çalışmalarında, hastaların \%81.0'inin erkek, \%19.0'unun kadın olduğu, \%33.4'ünün 21-30 yaş aralığında olduğu bildirilmiştir. Çalışmalarında incelenen hastalarda en sık mandibulada fraktür görüldüğü, mandibula fraktürlerinin ise \%31.2'sinin korpus, \%22.7'sinin simfiz, \%20.5'inin kondil ve \%13.7'sinin angulus bölgesinde olduğunu bildirmişlerdir.

Erol ve arkadaşlarının ${ }^{11}$, Ağız, Diş, Çene HastaIıkları ve Cerrahisi kliniğinde fasiyal fraktürü olan 2308 vakayı inceledikleri araştırmada, hastaların \%79.1'inin erkek, \%20.9'unun kadın olduğu; yaş aralıklarının sıklıklarının 0-10 yaş (\%27.4), 21-30 yaş (\%26.9), 1120 yaş (\%18.8) ve $31-40$ yaş (\%14.7) olduğu belirlenmiştir. Bu hastaların \%71.9'unda mandibulada ve \%.9.8'inde maksillada fraktür görüldüğü; mandibulada görülen fraktürlerin, \%34.3'ünün korpusta, \%23.6'sının simfizde, \%19.5'inin kondilde ve \%14.0'ünün angulus mandibulada meydana geldiği bildirilmiştir. Maksilladaki fraktürlerin ise çoğunlukla (\%43.0) maksiller alveolar proseste lokalize olduğunu vurgulamışlardır. Ortakoğlu ve arkadaşlarının ${ }^{16}$, maksillofasiyal fraktür nedeniyle tedavi gören 37 hastadaki 63 fraktürü inceledikleri çalışmada, fraktürlerin \%23.8'inin korpusta, \%20.6'sının kondilde, \%19.0'unun simfizde, $\% 15.8$ 'inin angulusta görüldüğü tespit edilmiştir. Askeri hastanede yapılan Ortakoğlu ve arkadaşlarının ${ }^{16}$ çalışmasındaki hastaların tümünün erkek olduğu, yaş ortalamasının 21.8 olduğu bildirilmiştir. Bu çalışmalarda, incelenen maksillofasiyal fraktürlerin teşhisinde kullanılan radyolojik yöntem ile ilgili bilgi mevcut değildir.

Çene ve yüz bölgesinde görülen fraktürler en sık çocuk ve gençlerde görülür. Genç ve erişkin yaş gruplarında ise erkek/kadın oranı 3/1'dir. Bunun nedeni, genellikle erkeklerin kadınlara göre dış ortamlarda daha fazla oluşu ve trafik kazalarından daha fazla etkilenmesidir ${ }^{1}$. Bu bulgu bizim çalışmamız ile uyuşmamaktadır. Bunun nedeninin, çalışmamızdaki çocuk hasta sayısının az olması, bu hastalarda KIBT 
çekiminden radyasyon dozundan dolayı kaçınılmasının olabileceğini düşünmekteyiz.

Literatürdeki araştırmalara benzer olarak, bu çalışmada da en fazla fraktürün mandibulada olduğu tespit edildi. Mandibula yüzün en büyük ve en kuvvetli kemiği olmasına rağmen, konumu ve çıkıntılı yapısı nedeniyle maksillofasiyal travmalar sonucunda, nazal kemik fraktürlerinden sonra en sık fraktür görülen ikinci kemiktir ${ }^{1}$.

Travma hastalarında uygun radyografik tetkikin seçimi, teşhis ve tedavi planlaması açısından çok önemli bir yere sahiptir ${ }^{10}$. Mandibula fraktürlerinin radyografik incelemesinde radyografların tanısal etkinliğinin ve tedaviye olan yararlılığının araştırıldığı bir çalışmada, panoramik radyografların zigomatik proses, tüber maksilla ve sfenoid kemiğin pterigoid proseslerinin süperpoze olarak mandibuler kondilin görüntülenmesinini zorlaştırdığı, ayrıca mandibuladaki minimal deplasmanlı veya oblik yöndeki fraktürlerin bu teknik ile net olarak izlenemediği bildirilmiştir. Bu nedenle, mandibular fraktürden şüphelenilen hastalarda KIBT görüntülerinin panoramik radyografiye göre daha doğru bilgi verdiği gösterilmiştir ${ }^{8}$. Travma hastalarında yaygın olarak kullanılan BT'ye göre radyasyon dozu düşük olan KIBT'de daha küçük ve izotropik vokseller kullanılır. Bu yüzden, maksillofasiyal bölgedeki sert dokuların değerlendirilmesinde KIBT'nin, BT'ye göre daha üstün olduğu gösterilmiştir ${ }^{17-20}$. Bununla birlikte, maksillofasiyal fraktürlerde KIBT kullanımının bazı sınırıııkları vardır. Mandibular kondillerin değerlendirilmesi gibi görüntüleme alanının büyük olması gerektiği durumlarda, voksel büyüklüğü de artacağından, KIBT'nin görüntü kalitesi düşmektedir. Bunun nedeni, KIBT cihazlarında FOV büyüdükçe voksel büyüklüğünün de artmasıdır ${ }^{8}$. Hekimlerin bu konuda dikkatli olmaları gerekmektedir.

Sonuç olarak, KIBT ile incelenen fraktür vakalarının çoğunluğunun genç-erişkin erkeklere ait olduğu saptandı. Fraktürlerin çoğunluğunun mandibulada lokalize olduğu, bunu zigoma ve pterigoid prosesin izlediği belirlendi. Diş hekimleri ve tıp hekimlerinin KIBT'nin maksillofasiyal fraktürlerdeki kullanımı hakkında bilgi sahibi olması vakaların değerlendirilmesi sırasında yararlı olacaktır.

\section{KAYNAKLAR}

1. Harorlı A, Akgül M, Yılmaz B, Bilge OM, Dağistan $S$, Çakur B, Çağlayan F, Miloğlu Ö, Sümbüllü MA. Ağız, Diş ve Çene Radyolojisi. 1.baskı İstanbul; Nobel Tıp Kitapevleri Tic. Ltd. Şti. 2014. sf. 484500.

2. Yaman F, Atılgan S, Yılmaz N, Görgün B. Mandibular kondil fraktürleri: Retrospektif analiz. Turkiye Klinikleri J Dental Sci 2007;13:48-54.

3. White SC, Pharoah MJ. Oral Radiology, Principles and Interpretation. 7 ed. St. Louis; Mosby/Elsevier: 2014. p. $570-81$.

4. Moudi E, Haghanifar S, Madani Z, Alhavaz A, Bijani A, Bagheri M. Assessment of vertical root fracture using cone-beam computed tomography. Imaging Sci Dent 2014;44:37-41.

5. Kambungton J, Janhom A, Prapayasatok S, Pongsiriwet $\mathrm{S}$. Assessment of vertical root fractures using three imaging modalities: cone beam CT, intraoral digital radiography and film. Dentomaxillofac Radiol 2012;41:91-5.

6. Zou X, Liu D, Yue L, Wu M. The ability of conebeam computerized tomography to detect vertical root fractures in endodontically treated and nonendodontically treated teeth: a report of 3 cases. Oral Surg Oral Med Oral Pathol Oral Radiol Endod 2011;111:797-801.

7. Yilmaz SY, Misirlioglu M, Adisen MZ. A diagnosis of maxillary sinus fracture with Cone-Beam CT: Case report and literature review. Craniomaxillofac Trauma Reconstr 2014;7:85-91.

8. Kaeppler G, Cornelius CP, Ehrenfeld M, Mast G. Diagnostic efficacy of cone-beam computed tomography for mandibular fractures. Oral Surg Oral Med Oral Pathol Oral Radiol 2013;116:98-104.

9. Eskandarlou A, Poorolajal J, Talaeipour AR, Talebi $S$, Talaeipour M. Comparison between cone beam computed tomography and multislice computed tomography in diagnostic accuracy of maxillofacial fractures in dried human skull: an in vitro study. Dent Traumatol 2014;30:162-8.

10. Sirin Y, Guven K, Horasan S, Sencan S. Diagnostic accuracy of cone beam computed tomography and conventional multislice spiral tomography in sheepmandibular condyle fractures. Dentomaxillofac Radiol 2010;39:336-42. 
11. Erol B, Özer N, Tanrıkulu R, Gülsün B, Atay Ç. Maksillo-fasiyal fraktürler: 2308 olgu ile ilgili retrospektif bir çalışma. Ulus Travma Acil Cerrahi Derg 1998;4:162-67.

12. Iida $S$, Kogo $M$, Sugiura $T$, Mima $T$, Matsuya $T$. Retrospective analysis of 1502 patients with facial fractures. Int J Oral Maxillofac Surg 2001;30:28690.

13. Olasoji HO, Tahir A, Arotiba GT. Changing picture of facial fractures in northern Nigeria. $\mathrm{Br} \mathrm{J}$ Oral Maxillofac Surg 2002;40:140-3.

14. Demir Z, Öktem F, Velidedeoğlu H, Çelebioğlu S. Maksillofasiyal kırığı olan 121 olgunun değerlendirilmesi ve literatürle karşılaştırılması. KBB-Forum 2008;7.

15. Li YS, Tian WD, Li SW, Liu L. Retrospective analysis of 3,958 patients with facial injuries. Zhonghua Kou Qiang Yi Xue Za Zhi 2006;41:385-7.

16. Ortakoğlu K, Saraçgil S, Üner E, Şener C. 37 hastada oluşan 63 maksillofasiyal fraktürde retrospektif bir çalışma. Cumhuriyet Üniversitesi Dişhekimliği Fakültesi Dergisi 2001;4:106-9.

17. Hashimoto K, Kawashima S, Kameoka S, Akiyama Y, Honjoya T, Ejima K, Sawada K. Comparison of image validity between cone beam computed tomography for dental use and multidetector row helical computed tomography. Dentomaxillofac Radiol 2007;36:465-71.

18. Liang $X$, Jacobs R, Hassan B, Li L, Pauwels R, Corpas L, Souza PC, Martens W, Shahbazian M, Alonso A, Lambrichts I. A comparative evaluation of Cone Beam ComputedTomography (CBCT) and Multi-Slice CT (MSCT) Part I. On subjective image quality. Eur J Radiol 2010;75:265-9.

19. Hahn W, Fricke-Zech S, Fialka-Fricke J, Dullin Ch, Zapf A, Gruber R, Sennhenn-kirchner S, KubeinMeesenburg D, Sadat-Khonsari R. Imaging of the midpalatal suture in a porcine model: flat-panel volume computed tomography compared with multislice computed tomography. Oral Surg Oral Med Oral Pathol Oral Radiol Endod 2009;108:4439.

20. Obenauer S, Dullin C, Alves F, Missbach-Guentner J, Grabbe E, Heuser M. Flat-panel-detector-based volumetric $\mathrm{CT}$ : performance evaluation of imaging for skeletal structures of small animals in comparison to multislice CT. Clin Imaging 2007;31:18-22.

\section{Yazışma Adresi:}

Arş. Gör. Uzm. Dt. Melih ÖZDEDE

Gazi Üniversitesi Diş Hekimliği Fakültesi

Ağız, Diş ve Çene Radyolojisi Anabilim Dalı

Emek/Çankaya/Ankara

TIf: 03122034157

e-posta: melihozdede@gmail.com 